\title{
Breaking down the classroom walls: How to train future media professionals in an interdisciplinary and applied way while fostering social change
}

\author{
Jorge Franganillo ${ }^{1,2}$, Lydia Sánchez ${ }^{1,2}$, M. Ángeles García Asensio ${ }^{1,2}$, Anna Marquès ${ }^{1}$ \\ ${ }^{1}$ Faculty of Information and Audiovisual Media, University of Barcelona, Spain, ${ }^{2}$ Research \\ Center on Information, Communication and Culture, University of Barcelona, Spain.
}

\begin{abstract}
This paper describes an effective methodological strategy that the Consolidated teaching innovation group in Communication and Audiovisual Media (In-COMAV), composed of a multidisciplinary teaching team, has been developing since 2016 within the Audiovisual Communication degree program offered by the University of Barcelona. This strategy consists of promoting service-learning projects within the context of various courses. Here we present the viability criteria established for the acceptance of projects oriented toward collaboration with organizations outside the university, the critical success factors and the results that this initiative has had on students, teachers, the university and society. Such results are perceived positively, yet there are still challenges and limitations to be overcome to ensure the continuity, sustainability and effectiveness of service-learning projects in higher education.
\end{abstract}

Keywords: teaching innovation; service-learning; unfair competition; interdisciplinary learning; applied learning. 


\section{Introduction}

As is widely known, universities play a social role. They are regarded as key institutions not only for personal and professional development, but also for promoting social change, so they serve a dual role. First of all, universities provide the professional training for high-level jobs. Secondly, and just as significantly, they train in skills and abilities that allow students to develop values and virtues that can enhance not just individual but also social well-being. Therefore, universities must promote educational innovation initiatives with a social impact, aimed at facilitating competency-based learning.

\section{Improving Audiovisual Communication students' career readiness}

With this in mind, for three years now a team of professors, now recognized as a consolidated teaching innovation group (In-COMAV), have been implementing some ideas to improve the professional preparation of students. This experience is taking place in the Audiovisual Communication degree program offered by the University of Barcelona's Faculty of Information and Audiovisual Media, whose objective is to train media professionals and content creators with a 4-year curriculum covering various professional profiles: scriptwriter, producer, director, visual and sound post-production designer, researcher and corporate communication specialist.

The set of initiatives this team is implementing to improve the career readiness of students includes training them in various forms of persuasive communication, promoting their participation in fiction and documentary film festivals and, more particularly, promoting the development of service-learning projects that combine learning and community service.

\section{Application of service-learning methodology in Audiovisual Communication}

The main innovation of service-learning lies in developing a well-articulated, coherent and original educational activity in which the pedagogical purpose is combined with solidarity (Puig et al., 2007; Martínez, 2009). As a methodological approach, service-learning makes the point that teaching cannot be limited to training students while locked in a classroom (Rodríguez \& Tiana, 2015).

In the context of the Audiovisual Communication degree, service-learning projects involve the production and direction of a short film with a clear social benefit. These projects therefore have a professionalizing role, as participating students are trained while working to meet real needs in their environment. They also promote knowledge transfer and interdisciplinary work, since students cooperate with professionals from different disciplines (historians, physicians, librarians, etc.). 
In the last three years, nine projects have been completed, and three new ones have been launched, involving a total of 50 students and 12 professors. This has meant collaborating with three other faculties and five other institutions (including hospitals, professional societies and neighborhood associations):

- $\quad$ Barcelona School of Nautical Studies, Polytechnic University of Catalonia

- $\quad$ Faculty of Medicine and Health Sciences, University of Barcelona

- School of Nursing, University of Barcelona

- Maritime Museum of Barcelona

- $\quad$ Language Services, University of Barcelona

- Official Association of Librarians-Documentalists of Catalonia

- Popular Historical Archive of Camp de la Bota and La Mina

- Podiatry Hospital, University of Barcelona

Altogether, these projects meet a variety of social needs: some of them seek to raise awareness about compliance with medical therapies, or against self-medication, others relate to coping strategies within a disadvantaged neighborhood, and others aim at disseminating local language and culture, just to mention a few.

Regardless of the topic covered, these projects share a common trait: all of them have been triggered by external proponents, although they have been submitted to a selection committee since not every proposal for collaboration could be accepted. Some of them lacked the social commitment and formative spirit necessary to fit into the educational model of servicelearning.

\section{Service-learning project requirements}

Proponents' requests often sound like a job offers without a salary. From what we have observed, such predatory behavior, seeking out free labor, is widespread. We therefore needed to ascertain some objective facts to decide on what was feasible (and what was not) before involving students and teachers in a new project. To this end, a set of guidelines was developed, first, to identify which proposals have real educational potential, and second, to avoid unfair competition with media professionals: in no case can any project ever replace the provision of a professional service.

This set of guidelines has proven useful for identifying what can (and what shouldn't) become a service-learning project and who can be a recipient of the service. In this sense, it might also be considered a compendium of best practices. 


\subsection{What a service-learning project must have}

- Value from an academic perspective. The initiative must have a pedagogical value and must facilitate the development of the specific and cross-cutting skills that the degree aims to confer.

- Social, political, cultural or economic impact. The resulting product must achieve something of public value; it must have some social, political, cultural or economic impact and must have the endorsement of a public institution, a social entity or an organization.

- $\quad$ Status as a teaching innovation project or a knowledge transfer project, which also means that students need to be provided with a training program.

- Natural development within the framework of a course, from both an academic and a chronological point of view (one academic semester or, only in exceptional cases, one academic year), with a professor who will act as mentor, guiding the students on their learning path.

- A proponent who is prepared to provide some funding, if necessary. On one hand, media schools are not production companies and shouldn't act as if they were. On the other, students should not be required to cover any expenses whatsoever. If there is the need to rent specific equipment, the proponent should cover the expenses. After all, the proponent is the project beneficiary.

\subsection{What a service-learning project is not}

- Work without salary. It should be clear that a service-learning project is not a job assignment. Students should not have to "respond to the proponent's orders." Even if they are working with a "client", it is still an academic project, not a business relationship. Students must conceptualize the product and do some research on the work to be carried out; they must play a leading role in the design of the product.

- A platform for commercial benefit. The product cannot be intended for any kind of promotion or economic benefit. It cannot be an advertisement or a promotional video. Even if there is no profit involved, the product cannot be intended for the sole benefit of the proponent. If the project is internal to the university, there is an appropriate formula: scholarships. In every project, students should get some benefit in terms of curriculum or experience. Even the media school itself could benefit in terms of brand enhancement.

- Unfair competition. The students' activity should not result in unfair competition with media professionals. The proponent should be aware that students are, after all, pursuing a learning activity within the framework of their education, so they may make mistakes and the final product might not be entirely satisfactory. Of course, the university will always ensure the quality of service but in no case should it be committed to providing a professional service. In any case, having this point stated 
in the guidelines is a protection for teachers and students. It should be borne in mind that most projects involve an investment of money, which would justify a complaint if the result is not fully satisfactory.

\section{Methodological advantages}

This initiative has an innovative approach as it emphasizes interdisciplinarity:

- The scope is encyclopedic, as the topics covered are widely varied. Normally, teaching innovation is focused on the discipline itself: nursing studies deals with nursing issues; architecture studies with architectural issues, etc. As teachers of Audiovisual Communication, we need to be open to all fields of knowledge.

- Participating teachers belong to varied areas of knowledge, so if we want to work on persuasive communication, we are not limited to oral communication, but also consider written and online communication, which involves personal branding and other issues.

- Participating students may come from different degree programs and work together on a joint project. In such cases, they are assessed using both joint and separate evaluation rubrics. The joint criteria are those related to the project development (cross-cutting skills), while the separate criteria are those associated with the specific skills of their corresponding degree programs.

- This methodology breaks out of the limits typically associated with specific courses: it breaks down the classroom walls and forces students (and also teachers) to engage in different disciplines and to engage in dialogue with external agents, which is inherent to working in the media industry.

\section{Results}

The results observed suggest a marked increase in students' enthusiasm and motivation. Students who participate in these initiatives are aware that the projects they carry out have a social utility and are used in communication campaigns. They perceive learning in an applied, practical way, which is more fun and motivating than ordinary exercises. Since they have to negotiate with a "client" (the proponent) to assess and determine what is really needed, they learn to analyze context, to formulate objectives, to break down complex situations and to design action plans.

In this way, students develop both social and professional skills. Also, as these projects are developed in the field of Audiovisual Communication, students have to build work teams covering all the usual profiles present on a professional film crew. This provides a valuable opportunity to learn role-oriented skills in a real working environment and to develop an 
aptitude for teamwork. As a side benefit, students participating in this type of initiative tend to earn higher grades (see Table 1). Furthermore, sometimes they are even willing to continue working on the same project after graduating, as has already been observed by other authors (Einfeld \& Collins, 2008).

Table 1. Grades earned in service-learning (SL) and non-SL projects

\begin{tabular}{lcccc}
\hline Course - academic year & SL projects & $\begin{array}{c}\text { SL projects } \\
\text { avg. grade }\end{array}$ & $\begin{array}{c}\text { Non-SL projects avg. } \\
\text { grade }\end{array}$ \\
\hline Project II & $2016-17$ & 2 & 9.1 & 7.56 \\
Project II & $2017-18$ & 1 & 8.04 & 6.83 \\
Final Project & $2017-18$ & 2 & 8.4 & 7.48 \\
Project II & $2018-19$ & 1 & 7.31 & 7.35 \\
Final Project & $2018-19$ & 2 & 7.37 & 7.65 \\
Idea to Screen & $2019-20$ & 1 & 9 & 7.19 \\
\hline
\end{tabular}

\section{Keys to success}

So far, this experience has allowed us to identify some keys to the success of service-learning initiatives:

- Planning and control. If a media school wants to engage in service-learning projects, it should do it gradually to make innovation sustainable and to guarantee its continuity. Developing service-learning projects needs an effective infrastructure. It is wiser to begin with a single project, even a large one, and complete it, than to start many small projects at once and end up not completing any. Also, the burden of management is multiplied with each new project, which is reason enough to focus on a few good projects, or only one, rather than spreading the resources out too thin.

- Receptivity. From inside the university it is sometimes hard to know all the needs of the outside world. In order to identify them, an exercise in humility is needed. The university must listen to the outside world and understand its particular needs, not to impose solutions, but to find a way to help solve problems. The university should 
not be working for external agents, but with them, as equals (those agents being, for instance, another faculty, a neighborhood or a medical department).

- Collaborative benefit. In this context of collaboration, all parties should win, and the benefit to be provided to each party has to be clearly defined from the start. First of all, the external agent wins because they are benefiting from this initiative. Students should get some benefit (learning, experience, personal growth) and should not be used as free labor. Moreover, their creations can be disseminated in different media and as such should be a valuable contribution to their CVs. Teachers get out of the classroom, negotiate with a "client" and guide the students in a professional context. Finally, by promoting SL, the university is developing new forms of training that are valuable in multiple ways.

- $\quad$ Rigor. Students do their part to face challenges and overcome problems, and they therefore should be trusted. However, this trust must be accompanied by rigor: their learning must be connected to the courses of their degree program and must also have clearly defined objectives and appropriate assessment procedures.

\section{Conclusion}

This experience with service-learning projects has allowed us to establish a set of useful guidelines for identifying collaboration proposals with educational value for Audiovisual Communication students. It is our belief that these guidelines can be equally applied to other disciplines as well, as they characterize what service-learning projects are really all about. On the other hand, the methodological advantages offered by these initiatives as teaching and learning experiences cannot be overemphasized: service-learning projects are conceived and developed in complex, real-life situations that demand interdisciplinarity and teamwork.

In this context of collaboration, one positive aspect deserves to be underlined: servicelearning is beneficial for all parties involved. Students learn to apply their knowledge: they solve real problems and also develop entrepreneurial and other skills. Teachers, for their part, can reinforce interdisciplinary work and academic coordination. University departments achieve greater institutional outreach by incorporating social engagement into their brand image and highlighting the relationship between knowledge and social welfare. Finally, society is another major beneficiary, since the university gives back to society just what is expected from it: the training of individuals who will contribute to collective well-being.

The results achieved show that students involved in service-learning projects are highly motivated and enthusiastic, as they are aware of the real social impact of their efforts. Students also benefit from applying social and professional skills in a way that is not possible in the closed context of the classroom. 
Universities are very much aware of the value of social engagement, and they are already looking for ways to incorporate this dimension into higher education (Arroyo, 2019). Such social engagement can be stated in the European diploma supplement, but to guarantee its sustainability as an educational practice, teachers who mentor service-learning projects also deserve recognition, since extra effort is needed to provide the personalized attention these projects require. This remains a challenge to be overcome in the future.

\section{References}

Arroyo, J. (2019). «Un currículum más allá del aula». El País, 14 de octubre. https://elpais.com/sociedad/2019/10/13/actualidad/1570981445_198065.html

Einfeld, E.; Collins, D. (2008). «The relationships between service-learning, social justice, multicultural competence, and civic engagement». Journal of College Student Development, n. 49, p. 95-109. https://doi.org/10.1353/csd.2008.0017

Martínez, M. (2009). «Aprenentatge servei i construcció de ciutadania activa a la universitat: la dimensió social i cívica dels aprenentatges acadèmics a la universitat». In: Martínez, Miquel (ed.). Aprenentatge servei i responsabilitat social de les universitats. Barcelona: Octaedro, p. 11-26.

Puig, J.M.; Batlle, R.; Bosch, C.; Palos, C. (2007). Aprendizaje servicio: educar para la ciudadanía. Barcelona: Octaedro.

Rodríguez, A.; Tiana, A. (2015). «Mutación digital», Telos: cuadernos de comunicación e innovación, n. 101, junio-septiembre, p. 48-51.

https://telos.fundaciontelefonica.com/archivo/numero101/mutacion-digital 